\title{
STUDY ON EFFECTS OF MICRON AND NANO ZINC OXIDE PIGMENTS ON AIR DRYING PROPERTY OF ALKYD PAINTS
}

\author{
Shambhu Sharan Kumar ${ }^{1}$, S. S. Narvi' and N.D. Pandey ${ }^{3}$ \\ ${ }^{1}$ Assistant Professor, Department of Chemistry, Birla Institute of Technology, Extension Centre, Allahabad, India \\ ${ }^{2,3}$ Professor, Department of Chemistry, Motilal Nehru National Institute of Technology, Allahabad, India \\ \{E-mail: 'shambhu66bit@rediffmail.com\}
}

\begin{abstract}
Alkyd resin based paints are most commonly used cost effective surface coatings in industrial segments as well as in our daily life for the purpose of protection and decoration of surfaces. In this research work, alkyd resin based air drying super white paint was prepared with micron sized $\mathrm{ZnO}$, nano $\mathrm{ZnO}$ and $\mathrm{ZnS}$ pigments to study the comparative air drying properties. The effects of employed micron and nano pigments on air drying properties as well as physical-mechanical performances of formulated alkyd paints were studied by comparing them on the basis of rigorous standard evaluation techniques as per ASTM and BIS methods. It has been brought into notice that zinc sulfide pigment shown a small effect on drying property of alkyd resin based paint and the curing schedule of paint does not so much depend upon the pigment volume concentration. On the other hand, nano zinc oxide pigment had shown great effects on drying time alongwith improvement in physical and mechanical properties of air drying alkyd paints, but the best result was observed of the paint containing nano ZnO-micron $\mathrm{ZnO}$ blended pigments synergistic arrangement.
\end{abstract}

Keywords: Nano ZnO pigment, nano paint, alkyd resin, air drying property.

\section{Introduction}

Alkyd resins are generally oil modified polyester formed by the reactions between a dibasic acid and a polyhydric alcohol and modified with drying or semi-drying oils or fatty acids [1].

$$
\underset{(\text { Alcohol) }}{\mathrm{ROH}}+\underset{\text { (Acid) }}{\text { HOOCR' }}=\underset{(\text { Ester })}{\text { RCOOR' }}+\underset{\text { (Water) }}{\mathrm{H}_{2} \mathrm{O}}
$$

Alkyds are most commonly used resins in the realm of paints and coatings. Whether it may be the air drying or stoving paint; alkyd resins are being used on tonnage basis in paint industries due to their availability and cost effectiveness. The main characteristic of these resins is their capabilities to perform an instantaneous reaction alongwith auto-oxidation by oxygen present in the air; which results in the configuration of crosslinked solid polymeric structures $[1,4,10]$.

Carbon-Carbon double bonds provide crosslinking reactive spots, which were established by oil-modifying mechanisms and sporadically by unsaturated polybasic acid presents into the polymeric configuration of the developed route for alkyds. The level and state of unsaturation of alkyd resin specify the vulnerability for drying by oxygen-absorption from air alongwith crosslinking reaction to provide a solid thin film [2]. The composition of fatty acid and palm stearin is nearly about $62 \%$ saturated and $38 \%$ unsaturated fatty acid. Palmstearins are more solid product of palm and palm-kernel oils. The core unsaturated acids have $32 \%$ oleic acid and $6 \%$ linoleic acid [3]. Palm-stearin has a very low level of un-saturation and palm stearin based alkyd resin can't be cured by air-drying [5, 6, 7]. For the purpose of air-drying, palm-stearin modified alkyd resin must give unsaturated carbon-carbon bonds into the core pendant chains of alkyd by adding collectively suitable constituents of paint, e.g., resins, pigments, solvents and additives to improve the drying property $[8,9,10]$.

Physical and chemical characteristics of organic coatings are generally improved by using very good quality of paint-constituents, i.e. pigment, solvents, resin, and additives. It also depends on optimum dispersion of pigments in resin media, has a certain effect on autooxidation reactions that take place in paints manufactured by adding unsaturated intermediates of alkyd media. Zinc oxide and zinc-stearate are the pervasive raw materials that are used as constituents of curing system in plastic formulations, in which their polymer-components contain unsaturated Carbon-Carbon bonds such as natural plastics $[12,13,14]$.

For the duration of last two decades, nano pigment particles have been synthesized and engrossed the great interest in formulations of different types of paints and coatings. Their applications in paints improve physical and chemical properties for getting extraordinary functions to protect the substrate surfaces in better way $[14,15,18]$. Thus such understanding encouraged the novel idea in exploring the effects of addition of micron and nano zinc oxide pigments into air-drying alkyd paint in order to renovate its drying property. Thus it has been possible to develop air drying paint based on palmstearin, which is a low-priced material and results in producing cost effective paints. So, in this work, palm- 
stearin based air drying alkyd paint was developed by applying conventional micron sized and nano zinc pigment particles into it. The most advantageous amount of nano $\mathrm{ZnO}$ and micron $\mathrm{ZnO}$ was determined. The effects of the used pigments on drying properties of alkyd paint were studied [2, 3, 5, 24].

\section{Experimental}

The resin was laboratory synthesized air drying long oil alkyd, based on pentaerythritol, phthalic anhydride, and maleic anhydride and was modified by palm stearin and castor oil. Its solid content was measured as $96 \%$ non volatile matter, and acid value of the used resin was 8.3. All other ingredients for formulation of air drying super white alkyd paints were the products of industrial grade, procured from industry. Conventional and nano paints were formulated with different approach in several steps by charging ball-mill with determined paint formula (Table 1).

Table 1: Formulation of alkyd resin based air drying paint

\begin{tabular}{|l|l|l|}
\hline Compositions & $\begin{array}{l}\text { Weight \% ratio } \\
\text { (in gm.): Micron }\end{array}$ & $\begin{array}{l}\text { Weight \% } \\
\text { ratio (in gm.): } \\
\text { Nano }\end{array}$ \\
\hline Micron $\mathrm{TiO}_{2}$ & 19.0 & 17.5 \\
\hline Nano $\mathrm{TiO}_{2}$ & -- & 01.0 \\
\hline Micron $\mathrm{ZnO}$ & 01.0 & -- \\
\hline Nano $\mathrm{ZnO}$ & -- & 01.0 \\
\hline Nano $\mathrm{SiO} 2$ & -- & 00.2 \\
\hline Nano $\mathrm{ZnS}$ & -- & 00.3 \\
\hline Alkyd resin & 57.5 & 57.5 \\
\hline Xylene & 20.0 & 20.0 \\
\hline $\begin{array}{l}\text { Solvent GR } \\
16 / 98\end{array}$ & 01.0 & 01.0 \\
\hline $\begin{array}{l}\text { Thixotropic } \\
\text { additive }\end{array}$ & 00.5 & 00.5 \\
\hline Silvoset-40 & 01.0 & 01.0 \\
\hline Total & $100 \%$ & $100 \%$ \\
\hline
\end{tabular}

Formulated paints were applied by a four-sided paint film applicator with slot width of 80-90 microns onto cleaned glass panels of $100 \times 100 \times 3 \mathrm{~mm}$ for drying time, hardness, and gloss measurements. Steel panels of $150 \times 75 \times 1 \mathrm{~mm}$ were used as substrate for the measure of adhesion and mechanical properties. Coated panels were kept for curing at room temperature under standard conditions in a laboratory (i.e., temperature: 25-27 degree Celsius and relative air humidity: $50 \%$ ).

Formulated paints were applied on smooth plastic substrate panels of $150 \times 75 \times 1 \mathrm{~mm}$ size using an air assisted spray gun coater. Successive application was carried out by a bar coater and then by air assisted spray gun at required time-intervals in order to get an appropriate film thickness to be able to peel-off the dried paint film as the dumb-bell shaped specimens of the substrate $[1,2,3,9]$.
Time measurement of paint-drying: The times required getting a tack-free surface and in hard-dry condition of the paint films applied on glass panels were measured according to ASTM-D-1640, [2,3].

Hardness measurement of the dried paint film: Hardness of the dried paint film surface is a feature which is considered with respect to satisfactoriness of paint-curing (crosslinking of paint vehicles alongwith film solidification). Advancement in the drying mechanism can be followed by measuring the hardness of the dried paint film. Hardness of the dried paint film applied on substrate surface was measured by using a pendulum hardness tester according to ASTM-D-4366-95 between 7 and 63 days after paint-application, i.e., as the time consumed, the hardness of paint-film continues to rise up getting its maximum value of hardness and after some days that does not increase considerably $[2,3,22]$.

Evaluation of mechanical properties: The paint-film applied on substrate surface was cut into the dumb-bell shape and the mechanical property evaluation was done using a universal testing machine in which cross head speed was fixed as $5.00 \mathrm{~mm}$ per minute.

Weathering resistance test: Dried paint film samples were put into a quick ultraviolet (QUV) weathering resistance testing machine in which the artificial environment varies at regular intervals i.e. the $\mathrm{UV}$ rays and temperature varies cyclically from $4^{\circ} \mathrm{C}$ to $50^{\circ} \mathrm{C}$ and relative humidity (RH) from 10 to $75 \%$. Each cycle was set for 48 hours and after the regular interval, tensile strength of the weathered-paint-film was measured [2, 3, 24].

\section{Results and Discussion}

Drying time of formulated paints has been examined and can be seen in figure 1. Obtained results demonstrate that both types of pigments influence the time of paint-drying. The zinc sulfide pigment does not have a particular effect on drying-time. On the other hand, both the micron and nano zinc oxide pigments affect and shrink the drying time, whereas nano $\mathrm{ZnO}$ particles perform to achieve a greater reduction in drying time. Drying time dropping of the nano $\mathrm{ZnO}$ particles modified paint film has been introduced appreciably by larger surface area due to the used nano particles in comparison to smaller surface area of micron zinc oxide pigment. High chemical potential may be a sign of higher chemical reactivity alongwith impulsive reactions. Forthcoming materials size to the nano level lead to grow the ratio of surface area to volume and this modification affects the performance of atoms and molecules present on the surface as particles in isolation and their interactions with other materials. Nano and micron particles shift into the area where quantum effects predominate. Larger surfaces provide additional reaction sites for the same volume. Contribution of surface energy to total energy content of nano materials, which determines its chemical reactivity greatly, comes 
into play, and leads to extensive acceleration of chemical reactions.

Hardness of dried paint films: Figures 2 and 3 refer the hardness testing result as a function of paint drying time measurement and pigment volume concentration (PVC) of the micron and nano zinc oxide pigments. Paint films containing both $\mathrm{ZnO}$ i.e., micron and nano pigments exhibited increased hardness if compared with film without the pigment, but the maximum hardness was attained in paint-film containing nano $\mathrm{ZnO}$.

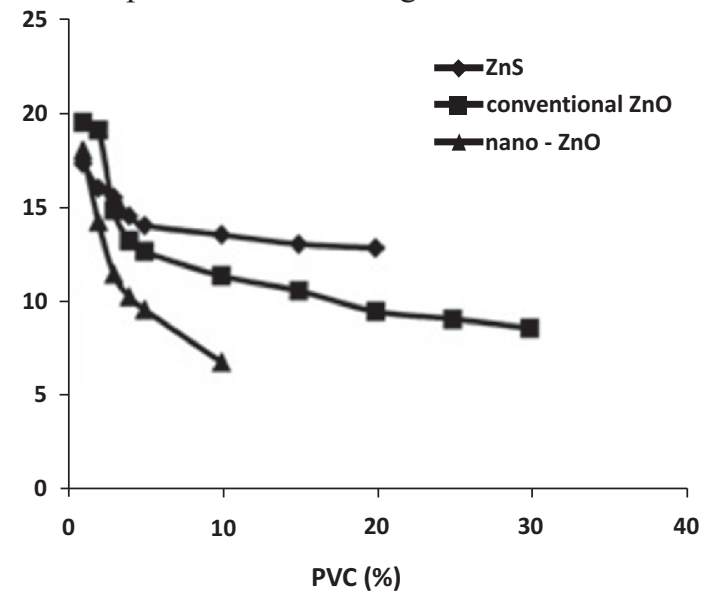

Fig. 1. Drying property of $\mathrm{ZnS}$ and $\mathrm{ZnO}$ coatings as the function of time and pigment-volume-concentration.

This outcome is reliable as well as comparable to the accomplished drying time result. Comparing two groups of the curves refer that the slope of the curves appears to be the same; signifying that the difference of the curves is simply due to the difference of the integrated particles but the improving mechanism of the drying process is not different. Palm-stearin-based alkyd resin paints

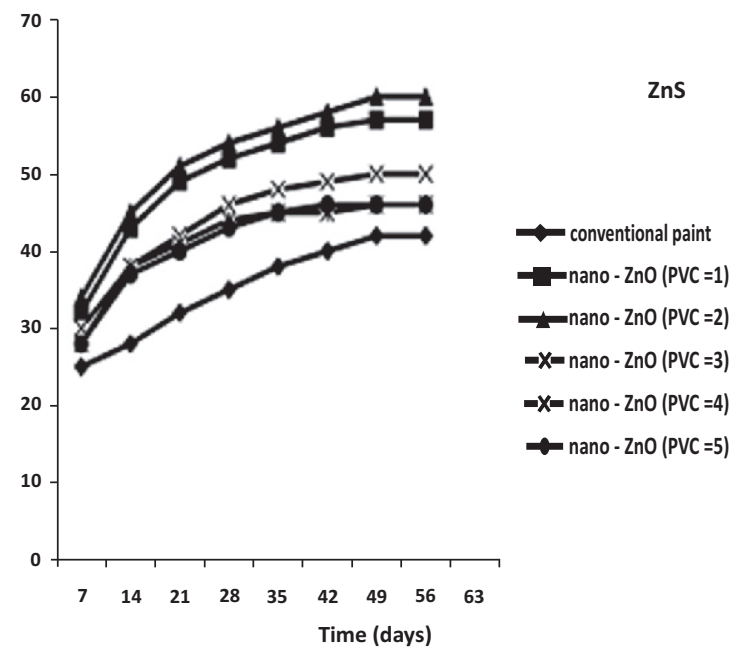

Fig.2. Hardness of dried paint film surfaces containing nano $\mathrm{ZnO}$ pigment as a function of time and PVC.
This result proves that the prime entity of the zinc pigments for accelerating the mechanism of paint drying is zinc-ion and the difference between them is correlated to their other entities, structural and physical uniqueness $[18,19,21]$.

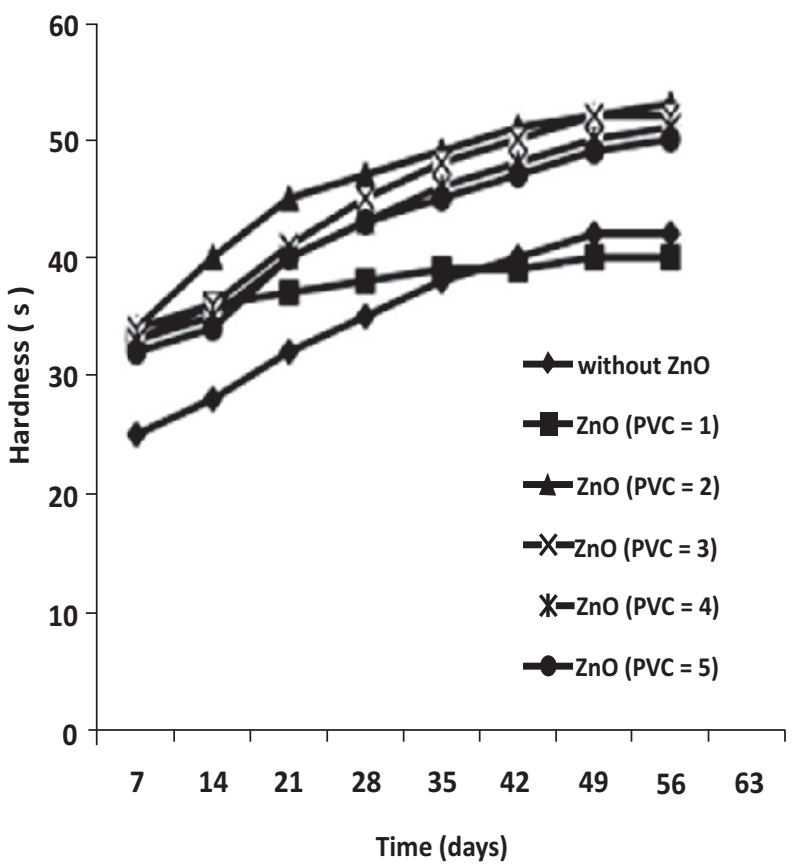

Fig. 3. Hardness of dry paint surface containing $\mathrm{ZnO}$ pigment as a function of time and PVC

Mechanical properties: Drying time and hardness test results referred the best outcome for nano $\mathrm{ZnO}$ pigment, exploration of mechanical properties concentrated on $\mathrm{ZnO}$ pigments only. Mechanical data derived from tensile stress-strain measurements are mentioned in Table 1. Results demonstrate that the tensile strength increases first, but with increasing the PVC of the nano $\mathrm{ZnO}$ decreases. The best possible PVC of nano $\mathrm{ZnO}$ is to give the highest mechanical property is $2 \%$ individually.

Table 2. Mechanical properties of dried paint films containing nano $\mathrm{ZnO}$

\begin{tabular}{|c|c|c|}
\hline PVC (\%) & $\begin{array}{l}\text { Tensile strength } \\
(\mathrm{M} \mathrm{Pa})\end{array}$ & $\begin{array}{l}\text { Elongation at } \\
\text { break (\%) }\end{array}$ \\
\hline 0.0 & 38.42 & 64.20 \\
\hline 1.0 & 72.83 & 58.58 \\
\hline 2.0 & 76.51 & 37.56 \\
\hline 3.0 & 50.53 & 60.80 \\
\hline 4.0 & 41.97 & 51.14 \\
\hline 5.0 & 35.11 & 45.16 \\
\hline
\end{tabular}


One of the prime factor that affect the performance of polymeric composites containing reinforcing particles, is the arrangement of the interface between particles and the matrix, because under mechanical stress, the micro-voids between particles or between the binder matrix, particles may become the origin of different yield and rupture. Nano particles, due to their ultra small sized, tend to occupy empty spaces such as pinholes and voids in the thin film of coating and provide as a bridge in the interrelated matrix, causing a reduction of the total free volume and a development in the crosslinking density of the dried paint film. As such, the dried nano-compositecoating has reduced chain segmental motion and improved mechanical properties [20,21]. In addition to this the nano $\mathrm{ZnO}$ particles can perform to prevent paint disaggregation during the drying process and result in a more homogenous dried film, which come forward with enhanced mechanical properties. More than $\mathrm{PVC}=2$, $\mathrm{ZnO}$ nano pigment particles cause aggregation in the dry paint film and lead to the deterioration in mechanical properties [19, 20,21].

Overall performance study: Observation of drying time assessment, hardness-measurement, and mechanical properties assessment confirmed when the $\mathrm{PVC}=2$; nano $\mathrm{ZnO}$ pigment produces the best performances. Hence, in order to inspect the performance effects, experimentations were concentrated on two types of coating-formulations: $1^{\text {st }}$ without pigment and $2^{\text {nd }}$ with $\mathrm{PVC}=2$ of nano $\mathrm{ZnO}$ pigment only.

Weathering resistance: Figure 4 refers that the variation of tensile strengths of the weathered paint films after five cycles. From the figure, it has been concluded that, if compared with its conventional corresponding items i.e. micron pigment; the nano $\mathrm{ZnO}$ pigment particles improved the weathering resistance of the paint film. The extremely small sizes of nano particles dispersed in nano organic coatings enables them to seal the voids and capillary spaces may present inside the coating-film and occupy small-hole defects created due to local shrinkage during the paint drying process. These affects the compact total free volume as well as an increase in the crosslinking density and finally, prevent substrate surfaces alongwith inside-deterioration of the paint film by weathering parameters $[19,20,22]$.

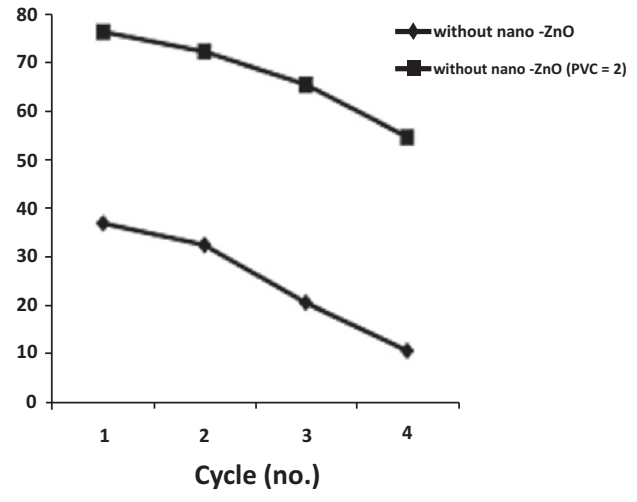

Fig. 4. Alteration of tensile strength of nano $\mathrm{ZnO}$ containing dried paint-film versus cycle number of weathering test.

\section{Conclusion}

On the basis of the observation-results found in the present work, it has been observed that zinc containing pigment system decreases the drying time of alkyd resin based paints, and among them nano $\mathrm{ZnO}$ is the most effective agent for reducing the time period. Keeping the physico-mechanical viewpoint, outstanding results were attained by the paint film containing nano $\mathrm{ZnO}$ pigment. The best possible quantity of this nano pigment was PVC $=2$, which provides the maximum decrease in drying time and appreciable increase in hardness, weathering resistance, and some other properties. The paint containing $\mathrm{ZnS}$ pigment also demonstrated the desired results. An optimum blend ratio of nano $\mathrm{ZnO}, \mathrm{ZnS}$ and micron $\mathrm{ZnO}$ pigment in a good formulation can produce improved results in paint with outstanding characteristics. So, it is recommended that rutile $\mathrm{TiO}_{2}$ with nano $\mathrm{TiO}_{2}$, nano $\mathrm{ZnO}$ and nano $\mathrm{SiO}_{2}$ as blend of pigment particles can be used in paint formulations for overall improvement in coating properties.

\section{Acknowledgments}

Author is grateful to my supervisor Prof. N.D. Pandey, Prof. S.S. Narvi, Prof. Parthsarthi Chakrabarti, the Director, M.N.N.I.T. Allahabad, and Prof. A.S. Khanna, Corrosion Engg. Labs of I.I.T. Bombay and R\&D Labs of Berger Paints Limited, Kolkata for providing their support and guidance to carry out the research work.

\section{References}

[1] A. S. Khanna, 'Nanotechnology in High Performance Paint Coatings", Asian J. Exp. Sci., vol. 21, no. 2, 2007, p. 25-32.

[2] ASTM International Standard (2010): "Chemical analysis of paints and paint materials", p. 817-96.

[3] ASTM Standard, "Standard practice for preparing, cleaning, and evaluating corrosion test specimens," American Society for Testing and Materials G1-03, 2011.

[4] D. Stoye, Fretig W. Paints, "Coatings \& Solvents", 2nd edition, Wiley: New York, 2007.

[5] H. Ismail, S. K. Kamal, Mark, S. E. Int. J. Polym. Mater. vol. 49 no. 2, p. 191-204.

[6] K. T. Teo, S. N. Gan, "Paint \& Ink. International", p. 26-30, 1997.

[7] S. N. Gan; Teo, K. T. "Surface Coatings Int.", vol. 82, no.1, p. 31-36, 1999.

[8] Gan, S.-N. Teo, K. T. "Paint Resin Technology", vol. 28, no.5, p. 283-292, 1999. 
[9] Gan, S. N. Tan, B. Y. "Journal of Applied Polymer Science", vol. 80, p. 2309-2315, 2001.

[10] El-Hai Abd, F. Sabbah, D. A. Abdel Rehim, N. S. "Int. Journal of Polym. Mater.", vol. 53, no. 10, p. 871-878, 2004.

[11] A. M. Issam, Nurul Kizrien, A. K. Mazlan, "Int. Polym. Plast. Technol. Eng.",vol. 50, no. 12,p. 1256-1261,2011.

[12] H. S. Patel, B. K. Patel, K. B. Desai, S. N. Int. "Journal of Polymer Mat." 2009, vol. 59, no. 1, p. $25-32$.

[13] G. Heideman, Datta, R. N. Noordermeer, et al “Appl. Polymer Sci.", 95, p. 1388-14040, 2005.

[14] Sabura Begum, P. M. Mohammad Yusuff, K. K. Joseph, R. “Int. J. Polym. Mater.", vol. 57, issue 12, p. 1083-1094, 2008.

[15] A. Chapman, Johnson, T. "The Role of Zinc in the Vulcanization of Rubbers Used in Tire Compounds", Tire Techno. Expo 2006, Sttugart, Germany, March 6-9, 2006.
[16] T. Xu, Xie, C. S. "Prog. Org. Coat.” 2003, 46, p. 297-301.

[17] H. J. Yu, Wang, L.; Shi, Q. Jiang, G. H. Zhao, Z. R. Dong, X. C. "Prog. Org. Coat." 2006, 55, p. 296-300.

[18] T. Knowles, "European Coatings Journal" 2006, 3, p. 16-18.

[19] S. Pilotek, Tabellion, F. "European Coatings Journal" 2005, 4, p. 170-172.

[20] D.R. Baer, Burrows, P. E. El-Azab, A. A. "Prog. Org. Coat."'2003, 47, p. 342-356.

[21] V. Stava, Vesely, D. Kalenda, P. "Pigment and Resin Technology", 2008, 37, p. 67-72.

[22] X. Shi, Nguyan, T. A. Suo, Z. Liu, Y. Avci, R. "Surface and Coating Technology" 2009, 204, p. 237-245.

[23] U. Konwar, U. Karak, N. "Int. J. Polym. Mater", 2011, vol.60, no. 10, p. 799-816.

[24] T. Rihayat, M.A. Sarri, et al, "Plastic Techno. Engg." 2006, vol. 45, no. 12, p. 1323-1326. 